\title{
Research Paper: Pathology \\ Differences in reproductive toxicology between alopecia drugs: an analysis on adverse events among female and male cases
}

\author{
Min W $\mathbf{u}^{1, *}$, Qingxiong Y $\mathbf{u}^{1, *}$ and Qingfeng $\mathbf{L i}^{1}$ \\ ${ }^{1}$ Department of Plastic and Reconstruction Surgery, Shanghai Ninth People's Hospital, Shanghai Jiao Tong University School \\ of Medicine, Shanghai, China \\ * These authors have contributed equally to this work
}

Correspondence to: Qingfeng Li, email: dr.liqingfeng@yahoo.com

Keywords: reproductive toxicity; alopecia; finasteride; minoxidil; FDA adverse event reporting system; Pathology Section

Received: August 04, 2016

Accepted: September 29, 2016

Published: October 12, 2016

\section{ABSTRACT}

\begin{abstract}
Alopecia is a dermatological condition with limited therapeutic options. Only two drugs, finasteride and minoxidil, are approved by FDA for alopecia treatment. However, little is known about the differences in adverse effects between these two drugs. We examined the clinical reports submitted to the FDA Adverse Event Reporting System (FAERS) from 2004 to 2014. For both female and males, finasteride was found to be more associated with reproductive toxicity as compared to minoxidil. Among male alopecia cases, finasteride was significantly more concurrent with several forms of sexual dysfunction. Among female alopecia cases, finasteride was significantly more concurrent with harm to fetus and disorder of uterus. In addition, drug-gene network analysis indicated that finasteride could profoundly disturb pathways related to sex hormone signaling and oocyte maturation. These findings could provide clues for subsequent toxicological research. Taken together, this analysis suggested that finasteride could be more liable to various reproductive adverse effects. Some of these adverse effects have yet to be warned in FDA-approved drug label. This information can help improve the treatment regimen of alopecia and post-marketing regulation of drug products.
\end{abstract}

\section{INTRODUCTION}

Alopecia refers to the unwanted loss of hair from the head or body, which affects both men and women [1]. Rather than physiological injury, the predominant impact of alopecia is psychological stress caused by the change in appearance. Psychological problems in some cases can deteriorate till the onset of severe symptoms [2]. Therefore, many affected subjects have strong willing to arrest progression of hair loss and stimulate hair growth, thus motivating basic research and drug development related to alopecia. The etiologies of alopecia are still largely unknown, but a series of hypotheses has been proposed to explain the causes [3]. Alopecia areata is considered an autoimmune disease, in which the immune system mistakenly attacks hair follicles [4]. Androgenic alopecia (a.k.a. male pattern baldness) may be a result of hair follicles miniaturization $[5,6]$ and microinflammation [7].

As a result of complicated etiologies, there are very limited therapeutic options so far. Finasteride and minoxidil are the only two drugs approved by Food and Drug Administration (FDA) for alopecia treatment. Finasteride oral tablet is approved for the treatment of benign prostatic hyperplasia and male pattern baldness. As a $5 \alpha$-reductase inhibitor, finasteride can prevent the conversion of testosterone to dihydrotestosterone, thus reducing androgen activity in the scalp [8]. Minoxidil is originally designed as an antihypertensive drug. Ever since hair regrowth is found as a side effect of treatment for hypertension, minoxidil has been broadly used for the topical treatment of alopecia. Many mechanisms of action have been proposed to explain the regrowth effect of minoxidil, including stimulation of blood flow in scalps [9], development of dermal papilla vascularization [10], enhanced hair follicular cycles [11] and potassium channel conductance [12]. Finasteride and minoxidil are effective in only a proportion of alopecia cases. But long after their discovery, there are still no new FDA-approved remedies.

Since finasteride and minoxidil are the two major treatments for alopecia, it is naturally a compelling issue to understand their clinical differences in both efficacy 
Table 1: The number of reports for female and male alopecia patients.

\begin{tabular}{|l|c|c|c|c|c|}
\hline & Male & Female & Percentage of Male & ORM-F $^{\mathbf{1}}$ & $\boldsymbol{P}_{\text {-value }} \mathbf{V}^{\mathbf{2}}$ \\
\hline All FAERS Reports & 1750808 & 2818346 & $38.3 \%$ & - & - \\
\hline Finasteride for alopecia treatment & 2076 & 60 & $97.2 \%$ & 55.70 & 0 \\
\hline Minoxidil for alopecia treatment & 92 & 99 & $48.2 \%$ & 1.50 & 0.0058 \\
\hline
\end{tabular}

${ }^{1}$ ORM-F $>1.0$ indicates that the proportion of male cases is higher than the overall level of all FAERS reports.

${ }^{2} P$-value, suggesting the significance of difference in gender composition, is determined using the Fisher's exact test.

and risks. In addition, it is essential for regulators, clinicians and consumers to understand the drug effects in men and women, respectively $[13,14]$. The differences in therapeutic effect between these two drugs were found to be sex-dependent. For male cases, a series of comparative studies suggested a better efficacy of finasteride [15-17]. In contrast, for female cases, several clinical studies suggested that finasteride was generally ineffective [18-20], while the efficacy of minoxidil was repeatedly reported $[21,22]$. On the other hand, however, the toxicological differences between finasteride and minoxidil were rarely addressed in previous studies, which was partially due to the difficulty in collecting clinical data about adverse effects from alopecia cases [23].

The FDA Adverse Event Reporting System (FAERS) is a computerized information database established by U.S. Government, which restores reports of adverse events spontaneously submitted by patients and healthcare professionals. Ever since 2004, the continuous operation of FAERS has achieved an enormous data collection, so as to support FDA's post-marketing safety surveillance for approved drug products. Once a pharmacovigilance signal was detected, a more rigorous investigation could be conducted. In the meantime, FAERS also promoted clinical studies worldwide [24] and lead to a series of publications regarding various drugs and adverse effects [25-27]. Because of the increasingly broad application of FAERS data, the openFDA initiative was officially launched in June 2014, which provided an official application programming interface (API) to access the raw data of adverse event reports in a structured format.

In the present study, we were enabled by openFDA to retrieve adverse events reported to FAERS by alopecia cases. By comparing the adverse events of finasteride and minoxidil, we identified a series of common adverse reactions that were significantly more concurrent with one drug than the other. In particular, many of these adverse reactions were directly related to female or male reproductive system. The differences in reproductive toxicology between alopecia drugs reiterated the precautions of clinical drug use and warranted subsequent research on the underlying toxicological mechanisms.

\section{RESULTS}

\section{The gender composition of case reports}

We primarily examined the gender composition of alopecia cases. The numbers of reports for both female and male cases were counted (Table 1), while the reports without gender information were excluded for analysis (see Methods). Adverse events of male patients accounted for only $38.3 \%$ of the total FAERS reports. But among alopecia cases, the reports of male cases comprised a significantly higher proportion. Nearly half of minoxidil related reports (i.e., 48.2\%) and most finasteride related reports (i.e., 97.2\%) were submitted by male cases. Such an highly biased gender composition of finasteride related reports should be attributed to the fact that finasteride was approved for alopecia in men only [28].

Then, we scrutinized the top 10 most commonly reported adverse events among female and male alopecia cases exposed to either finasteride or minoxidil (Table 2). It appeared that female and male cases were prone to different adverse effects. In addition, a number of adverse effects were directly related to reproductive system, such as 'abortion induced' among females and 'erectile dysfunction' among males. Then, we compared the reports of finasteride and minoxidil, so as to find whether certain adverse effects were significantly more associated with one drug than the other. Due to the intrinsic gender difference in physiology, we analyzed the data of female and male cases separately.

\section{The adverse events among male cases}

Estimating safety risk from spontaneous reports is not straightforward, since the number of reported events is correlated to the total number of patients taking the drug. For example, if a blockbuster drug is used by a large number of patients, the number of adverse events of that drug may naturally be relatively large. For that reason, we calculated the proportion of a certain adverse effect in the 
Table 2: The top 10 most commonly reported adverse events among female and male alopecia patients using finasteride or minoxidil.

\begin{tabular}{|c|l|l|l|l|}
\hline \multirow{2}{*}{ Rank } & \multicolumn{2}{|c|}{ Finasteride } & \multicolumn{1}{c|}{ Manoxidil } \\
\cline { 2 - 5 } & \multicolumn{1}{|c|}{ Female } & \multicolumn{1}{c|}{ Male } \\
\hline 1 & Abortion Induced & Erectile Dysfunction & Swelling Face & $\begin{array}{l}\text { Erectile } \\
\text { Dysfunction }\end{array}$ \\
\hline 2 & Abortion Spontaneous & Sexual Dysfunction & Dermatitis Contact & Depression \\
\hline 3 & Paternal Drugs Affecting Fetus & Depression & Arthralgia & Dizziness \\
\hline 4 & Uterine Cervix Stenosis & Anxiety & Palpitations & Anxiety \\
\hline 5 & Menstruation Irregular & Cognitive Disorder & Dizziness & Libido Decreased \\
\hline 6 & Menorrhagia & Libido Decreased & Nausea & Hypoesthesia \\
\hline 7 & Endometrial Hypertrophy & Loss Of Libido & Tachycardia & Headache \\
\hline 8 & Phalangeal Agenesis & Fatigue & Weight Increased & Dermatitis Contact \\
\hline 9 & Fatigue & Semen Volume Decreased & $\begin{array}{l}\text { Visual } \\
\text { Reduced }\end{array}$ & Chorioretinopathy \\
\hline 10 & Arthritis & Ejaculation Disorder & Pruritus & Skin Disorder \\
\hline
\end{tabular}

total reports of a drug, in order to normalize the difference in the amount of usage between individual drugs. Thus, the proportion value of finasteride was compared to that of minoxidil, which lead to the proportional reporting ratio (PRR) [29], along with 95\% confidence interval (CI) and significance level (see Methods). As a qualitative indicator, PRR showed which drug was more concurrent with a certain adverse effect.

Among male cases, finasteride was found to be more frequently reported for reproductive adverse effects (Table 3). For instance, 'erectile dysfunction' was reported by $50.39 \%$ of the cases receiving finasteride treatment, while this proportion for minoxidil was only $4.35 \%$. A PRR of 11.59 (95 CI: 4.44 - 30.25) indicated a significant difference between these two drugs $\left(P=8.31 \times 10^{-12}\right)$. Likewise, 'ejaculation disorder' $(\mathrm{PRR}=7.67 ; P=0.013)$, 'libido decreased' $\left(\mathrm{PRR}=21.98 ; P=1.02 \times 10^{-7}\right)$, 'loss of libido' $\left(\mathrm{PRR}=13.52 ; P=8.22 \times 10^{-5}\right)$, 'semen volume decreased' $\left(\mathrm{PRR}=8.51 ; P=5.78 \times 10^{-3}\right)$ and 'sexual dysfunction' (not reported for minoxidil; $P=2.54 \times 10^{-15}$ ) were also more concurrent with finasteride as compared to minoxidil. These results suggested that finasteride should be used by males with more caution.

In addition to reproductive toxicity, some psychiatric reactions were not emphasized in FDAapproved drug label [28] but frequently reported by cases exposed to finasteride, including 'anxiety' (PRR $\left.=29.74 ; P=4.17 \times 10^{-10}\right)$, 'depression' $(\mathrm{PRR}=10.74 ; P$ $=5.55 \times 10^{-9}$ ) and 'cognitive disorder' (not reported for minoxidil; $P=1.75 \times 10^{-10}$ ). Only a few adverse effects were apparently more reported by minoxidil users, such as 'dermatitis contact' $\left(\mathrm{PRR}=0.06 ; P=1.58 \times 10^{-5}\right)$ and 'chorioretinopathy' $\left(\mathrm{PRR}=0.02 ; P=5.39 \times 10^{-7}\right)$. These adverse effects should also be taken into consideration in selecting the appropriate treatment.

\section{The adverse events among female cases}

On the other hand, we also examined the adverse effects among female cases. Even though finasteride has not been officially approved for use by women, a number of female cases exposed to finasteride were still found in FAERS data. Compared with minoxidil, finasteride exhibited significantly negative effect on female reproductive system (Table 4). Fetal toxicity, characterized by 'abortion induced' $\left(\mathrm{PRR}=9.07 ; P=1.93 \times 10^{-3}\right)$, 'abortion spontaneous' (PRR $=6.60 ; P=0.016)$ and 'paternal drugs affecting fetus' (not reported for minoxidil; $P=8.89 \times 10^{-3}$ ), was more concurrent with finasteride than minoxidil. Moreover, finasteride may affect uterus, leading to more reports of 'uterine cervix stenosis' (not reported for minoxidil; $P=0.022$ ) and 'endometrial hypertrophy' (not reported for minoxidil; $P=0.022$ ). These results revealed the safety risks of unapproved use of finasteride in female cases, especially in pregnant women. In contrast, minoxidil-biased risk was not widely detected. 'Swelling face', as a relatively minor safety concern, was the only adverse effect significantly more reported by female cases exposed to minoxidil (not reported for finasteride; $P=$ 0.027).

\section{Drug-gene network and functional enrichment analysis}

The aim of this study was not only to identify the relative higher risk of finasteride, but more importantly, to better understand how finasteride interfered with the normal function of reproductive system. Almost all drugs act through the interactions with numerous proteins in human body encoded by different genes. In recent years, 
Table 3: The comparison between adverse events reported by male alopecia patients exposed to finasteride and minoxidil

\begin{tabular}{|c|c|c|c|c|c|c|}
\hline Adverse Effect & Drug & Affected Cases & Total Cases & Proportion $^{1}$ & PRR $(95 \% \text { CI })^{2}$ & $P$-value ${ }^{3}$ \\
\hline \multirow{2}{*}{ Anxiety } & Finasteride & 671 & 2076 & $32.32 \%$ & \multirow{2}{*}{$29.74(4.23-209.10)$} & \multirow{2}{*}{$4.17 \times 10^{-10 * * *}$} \\
\hline & Minoxidil & 1 & 92 & $1.09 \%$ & & \\
\hline \multirow{2}{*}{ Chorioretinopathy } & Finasteride & 3 & 2076 & $0.14 \%$ & \multirow{2}{*}{$0.02(0.01-0.08)$} & \multirow{2}{*}{$5.39 \times 10^{-7 * * *}$} \\
\hline & Minoxidil & 6 & 92 & $6.52 \%$ & & \\
\hline \multirow{2}{*}{ Cognitive Disorder } & Finasteride & 607 & 2076 & $29.24 \%$ & \multirow{2}{*}{ N/A } & \multirow{2}{*}{$1.75 \times 10^{-10 * * *}$} \\
\hline & Minoxidil & 0 & 92 & $0.00 \%$ & & \\
\hline \multirow{2}{*}{ Depression } & Finasteride & 727 & 2076 & $35.02 \%$ & \multirow{2}{*}{$10.74(3.52-32.74)$} & \multirow{2}{*}{$5.55 \times 10^{-9 * * *}$} \\
\hline & Minoxidil & 3 & 92 & $3.26 \%$ & & \\
\hline \multirow{2}{*}{ Dermatitis Contact } & Finasteride & 8 & 2076 & $0.39 \%$ & \multirow{2}{*}{$0.06(0.02-0.17)$} & \multirow{2}{*}{$1.58 \times 10^{-5 * * *}$} \\
\hline & Minoxidil & 6 & 92 & $6.52 \%$ & & \\
\hline \multirow{2}{*}{ Dizziness } & Finasteride & 67 & 2076 & $3.23 \%$ & \multirow{2}{*}{$0.59(0.24-1.43)$} & \multirow{2}{*}{0.24} \\
\hline & Minoxidil & 5 & 92 & $5.43 \%$ & & \\
\hline \multirow{2}{*}{ Ejaculation Disorder } & Finasteride & 173 & 2076 & $8.33 \%$ & \multirow{2}{*}{$7.67(1.09-54.15)$} & \multirow{2}{*}{$0.013^{*}$} \\
\hline & Minoxidil & 1 & 92 & $1.09 \%$ & & \\
\hline \multirow{2}{*}{ Erectile Dysfunction } & Finasteride & 1046 & 2076 & $50.39 \%$ & \multirow{2}{*}{$11.59(4.44-30.25)$} & \multirow{2}{*}{$8.31 \times 10^{-12 * * *}$} \\
\hline & Minoxidil & 4 & 92 & $4.35 \%$ & & \\
\hline \multirow{2}{*}{ Fatigue } & Finasteride & 232 & 2076 & $11.18 \%$ & \multirow{2}{*}{$5.14(1.30-20.35)$} & \multirow{2}{*}{$6.88 \times 10^{-3 * *}$} \\
\hline & Minoxidil & 2 & 92 & $2.17 \%$ & & \\
\hline \multirow{2}{*}{ Headache } & Finasteride & 84 & 2076 & $4.05 \%$ & \multirow{2}{*}{$0.62(0.28-1.38)$} & 028 \\
\hline & Minoxidil & 6 & 92 & $6.52 \%$ & & 0.20 \\
\hline Hunontheris & Finasteride & 40 & 2076 & $1.93 \%$ & $044(0.16 \quad 120)$ & 0.12 \\
\hline пуроеstпеsid & Minoxidil & 4 & 92 & $4.35 \%$ & $0.44(0.10-1.20)$ & 0.12 \\
\hline I ibido Doorod & Finasteride & 496 & 2076 & $23.89 \%$ & $2108(212 \quad 15462)$ & $102 \times 10-7 * * *$ \\
\hline Lividu Decieased & Minoxidil & 1 & 92 & $1.09 \%$ & $21.90(5.12-104.02)$ & 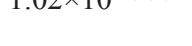 \\
\hline I oce of I ihid & Finasteride & 305 & 2076 & $14.69 \%$ & 1252 (1) 070502$)$ & Q $22 \times 10-5 * * *$ \\
\hline LOSS OI LIOUICO & Minoxidil & 1 & 92 & $1.09 \%$ & $10.52(1.92-93.25)$ & $0.22 \wedge 10$ \\
\hline Volume & Finasteride & 192 & 2076 & $9.25 \%$ & $851(121,6005)$ & $578 \times 10-3 * *$ \\
\hline Decreased & Minoxidil & 1 & 92 & $1.09 \%$ & $0.01(1.21-00.00)$ & $3.10 \times 10$ \\
\hline Sovul Dycfunction & Finasteride & 956 & 2076 & $46.05 \%$ & $N / A$ & $54 \times 10-15 * * *$ \\
\hline Sexuar Dysitutetion & Minoxidil & 0 & 92 & $0.00 \%$ & IV/A & $2.04 \times 10$ \\
\hline & Finasteride & 25 & 2076 & $1.20 \%$ & $\begin{array}{lllllll}0 & 27 & 7 & 1 & 1 & 1\end{array}$ & 010 \\
\hline SKIII DISOICLC & Minoxidil & 3 & 92 & $3.26 \%$ & $0.3 /(0.11-1.20)$ & 0.12 \\
\hline
\end{tabular}

${ }^{1}$ The proportion value is computed as the number of affected cases divided by the number of total cases.

${ }^{2}$ A PRR significantly greater (or lower) than 1.0 means the risk is higher for finasteride (or minoxidil).

$3 *, p<0.05 ; * *, p<0.01 ; * * *, p<0.001$

the integrated analysis of drug-gene interactions has provided many applications in toxicological research [30]. To extend our knowledge of reproductive toxicity, we constructed a drug-gene network [31] and explored a number of genes directly or indirectly interrupted by finasteride (see Materials and Methods). First, we searched the PharmGKB database (https://www.pharmgkb.org/) and the DrugBank database (http://www.drugbank.ca/) to extract the finasteride-associated genes (FAGs) with known pharmacokinetic and pharmacodynamic evidences. Then, the FAGs were overlaid into the context of human protein-protein interactions (PPIs) to recruit their neighbor proteins, whose encoding genes were defiend as indirectly associated genes (IAGs) of finasteride. At last, all FAGs and IAGs were integrated into a network with 260 nodes (259 genes and 1 drug) and 262 edges, which characterized the toxicology of finasteride (Figure 1A). It is common knowledge that the topology of true biological networks is obviously different from that of random networks. The topological coefficients (Figure 1B) and betweenness centrality (Figure 1C) of the finasteride-centered network approximately followed power law distributions [32]. This 
Table 4: The comparison between adverse events reported by female alopecia patients exposed to finasteride and minoxidil

\begin{tabular}{|c|c|c|c|c|c|c|}
\hline Adverse Effect & Drug & Affected Cases & Total Cases & Proportion $^{1}$ & PRR $(95 \% \text { CI })^{2}$ & $P$-value ${ }^{3}$ \\
\hline \multirow{2}{*}{ Abortion Induced } & Finasteride & 11 & 60 & $18.33 \%$ & \multirow{2}{*}{$9.07(2.08-39.53)$} & \multirow{2}{*}{$1.93 \times 10^{-3 * *}$} \\
\hline & Minoxidil & 2 & 99 & $2.02 \%$ & & \\
\hline \multirow{2}{*}{ Abortion Spontaneous } & Finasteride & 8 & 60 & $13.33 \%$ & \multirow{2}{*}{$6.60(1.45-30.06)$} & \multirow{2}{*}{$0.016^{*}$} \\
\hline & Minoxidil & 2 & 99 & $2.02 \%$ & & \\
\hline \multirow{2}{*}{ Arthralgia } & Finasteride & 3 & 60 & $5.00 \%$ & \multirow{2}{*}{$0.55(0.15-1.95)$} & \multirow{2}{*}{0.54} \\
\hline & Minoxidil & 9 & 99 & $9.09 \%$ & & \\
\hline \multirow{2}{*}{ Arthritis } & Finasteride & 3 & 60 & $5.00 \%$ & \multirow{2}{*}{$\mathrm{N} / \mathrm{A}$} & \multirow{2}{*}{0.057} \\
\hline & Minoxidil & 0 & 99 & $0.00 \%$ & & \\
\hline \multirow{2}{*}{ Dermatitis Contact } & Finasteride & 2 & 60 & $3.33 \%$ & \multirow{2}{*}{$0.37(0.08-1.66)$} & \multirow{2}{*}{0.33} \\
\hline & Minoxidil & 9 & 99 & $9.09 \%$ & & \\
\hline \multirow{2}{*}{ Dizziness } & Finasteride & 2 & 60 & $3.33 \%$ & \multirow{2}{*}{$0.41(0.09-1.87)$} & \multirow{2}{*}{0.33} \\
\hline & Minoxidil & 8 & 99 & $8.08 \%$ & & \\
\hline \multirow{2}{*}{ Endometrial Hypertrophy } & Finasteride & 4 & 60 & $6.67 \%$ & \multirow{2}{*}{$\mathrm{N} / \mathrm{A}$} & \multirow{2}{*}{$0.022 *$} \\
\hline & \begin{tabular}{|l|} 
Minoxidil \\
\end{tabular} & 0 & 99 & $0.00 \%$ & & \\
\hline \multirow{2}{*}{ Fatigue } & Finasteride & 3 & 60 & $5.00 \%$ & \multirow{2}{*}{$0.99(0.25-3.99)$} & \multirow{2}{*}{1.00} \\
\hline & Minoxidil & 5 & 99 & $5.05 \%$ & & \\
\hline \multirow{2}{*}{ Menorrhagia } & Finasteride & 4 & 60 & $6.67 \%$ & $660(076-5768)$ & 0077 \\
\hline & Minoxidil & 1 & 99 & $1.01 \%$ & $0.00(0.10-5 / .08)$ & 0.011 \\
\hline Menstruation Irreoular & Finasteride & 4 & 60 & $6.67 \%$ & $660(076-5768)$ & 0077 \\
\hline Menstruation irreguiar & Minoxidil & 1 & 99 & $1.01 \%$ & $0.00(0.10-5 / .08)$ & 0.011 \\
\hline Nourgo & Finasteride & 2 & 60 & $3.33 \%$ & $0.47(0.10 \quad 210)$ & 0.40 \\
\hline Nausea & Minoxidil & 7 & 99 & $7.07 \%$ & $0.4 /(0.10-2.19)$ & 0.49 \\
\hline Palnitations & Finasteride & 0 & 60 & $0.00 \%$ & 000 & 052 \\
\hline Palpitations & Minoxidil & 8 & 99 & $8.08 \%$ & 0.00 & 0.52 \\
\hline Paternal Drugs Affecting & Finasteride & 5 & 60 & $8.33 \%$ & & $880 \times 10^{-3} * *$ \\
\hline Fetus & Minoxidil & 0 & 99 & $0.00 \%$ & N/A & $0.89 \times 10=0.090$ \\
\hline Phalangeal A genecis & Finasteride & 3 & 60 & $5.00 \%$ & $N / A$ & 0057 \\
\hline Pnarangeal Agenesis & Minoxidil & 0 & 99 & $0.00 \%$ & N/A & 0.001 \\
\hline Pruritus & Finasteride & 1 & 60 & $1.67 \%$ & $033(004-276)$ & 041 \\
\hline Prumitus & Minoxidil & 5 & 99 & $5.05 \%$ & $0.55(0.04-2.10)$ & 0.41 \\
\hline & Finasteride & 0 & 60 & $0.00 \%$ & 000 & $0027 *$ \\
\hline Swelling race & Minoxidil & 9 & 99 & $9.09 \%$ & 0.00 & $0.02 / *$ \\
\hline Tachycardia & Finasteride & 0 & 60 & $0.00 \%$ & 000 & 0087 \\
\hline racmycarara & Minoxidil & 6 & 99 & $6.06 \%$ & 0.00 & 0.001 \\
\hline Uterine Cervix Stenesis & Finasteride & 4 & 60 & $6.67 \%$ & $N / A$ & $0022 *$ \\
\hline Uteme Cenvix stenosis & Minoxidil & 0 & 99 & $0.00 \%$ & IN/A & 0.022 \\
\hline Visual Acuity Reduced & Finasteride & 0 & 60 & $0.00 \%$ & 000 & 016 \\
\hline Visual Acuity Keduced & Minoxidil & 5 & 99 & $5.05 \%$ & 0.00 & 0.10 \\
\hline & Finasteride & 0 & 60 & $0.00 \%$ & 000 & 016 \\
\hline weignt increased & Minoxidil & 5 & 99 & $5.05 \%$ & 0.00 & 0.10 \\
\hline
\end{tabular}

${ }^{1}$ The proportion value is computed as the number of affected cases divided by the number of total cases.

${ }^{2}$ A PRR significantly greater (or lower) than 1.0 means the risk is higher for finasteride (or minoxidil).

$3 *, p<0.05 ; * *, p<0.01$ 
Table 5: The functional annotations enriched with genes interrupted by finasteride.

\begin{tabular}{|c|c|c|c|}
\hline & Genes in the category & \begin{tabular}{|l|} 
OR \\
enrichment
\end{tabular} & $\begin{array}{l}\text { Adjusted } \\
P \text {-value } \\
\end{array}$ \\
\hline \multicolumn{4}{|l|}{ GO Terms } \\
\hline $\begin{array}{l}\text { Intracellular steroid hormone receptor } \\
\text { signaling pathway (GO:0030518) }\end{array}$ & $\begin{array}{l}\text { EP300, PHB, SMARCA4, KAT5, UBE2I, } \\
\text { SRC, CCNE1, PARK7, TRIM68, TADA3, } \\
\text { CALR, PIAS1, NR0B1, RB1, UBE3A, } \\
\text { NCOA6, CTNNB1, RNF4, GRIP1, } \\
\text { MED24, RAN, MED1, FKBP4, NCOA2, } \\
\text { SIRT1, SKP2, FHL2, BRCA1, CDK7, } \\
\text { KDM3A, NCOA3, RNF6, NCOA4, } \\
\text { DAXX, PMEPA1, PIAS2, HDAC1, } \\
\text { AR, NCOA1, NR0B2, RNF14, FOXA1, } \\
\text { TGFB1I1 }\end{array}$ & 24.73 & $1.24 \times 10^{-47}$ \\
\hline $\begin{array}{l}\text { Androgen receptor signaling pathway } \\
\text { (GO:0030521) }\end{array}$ & $\begin{array}{l}\text { EP300, PHB, SMARCA4, KAT5, CCNE1, } \\
\text { PARK7, TRIM68, PIAS1, RB1, UBE3A, } \\
\text { CTNNB1, RNF4, MED24, GRIP1, RAN, } \\
\text { MED1, FKBP4, NCOA2, SIRT1, FHL2, } \\
\text { BRCA1, CDK7, KDM3A, NCOA3, } \\
\text { RNF6, NCOA4, PMEPA1, DAXX, PIAS2, } \\
\text { HDAC1, AR, NR0B2, NCOA1, RNF14, } \\
\text { TGFB1I1 }\end{array}$ & 32.91 & $2.00 \times 10^{-44}$ \\
\hline \multicolumn{4}{|c|}{\begin{tabular}{|l|l|} 
KEGG Pathways & \\
\end{tabular}} \\
\hline $\begin{array}{lll}\text { Steroid } & \text { hormone } & \text { biosynthesis } \\
\text { (hsa00140) } & & \\
\end{array}$ & $\begin{array}{l}\text { AKR1D1, CYP3A7, CYP3A5, AKR1C1, } \\
\text { SRD5A2, AKR1C3, SRD5A1, CYP3A4 } \\
\end{array}$ & 23.88 & $7.16 \times 10^{-9}$ \\
\hline Oocyte meiosis (hsa04114) & \begin{tabular}{|lll} 
AR, YWHAQ, PPP1CA, MAPK1, \\
PRKACA, CCNE1, CALM1
\end{tabular} & 10.45 & $1.43 \times 10^{-5}$ \\
\hline $\begin{array}{ll}\text { Progesterone-mediated } & \text { oocyte } \\
\text { maturation (hsa04914) } & \end{array}$ & $\begin{array}{l}\text { HSP90AA1, CDC25B, AKT1, MAPK1, } \\
\text { PRKACA, RAF1 }\end{array}$ & 11.66 & $3.27 \times 10^{-5}$ \\
\hline
\end{tabular}

${ }^{1}$ The $p$-values were calculated by hypergeometric test and adjusted with the Benjamini-Hochberg procedure.

suggested that a few hubs in this network linked to most of other nodes, which is one of the most distinguishing characteristics of scale-free biological networks [33].

To interpret the biological importance of this network, we queried the FAGs and IAGs in the WebGestalt online server (see Materials and Methods). Enrichment analyses for the KEGG pathways and Gene Ontology (GO) terms were performed (Table 5). Regarding reproductive toxicity in men, we found that the FAGs and IAGs were significantly enriched in the 'steroid hormone
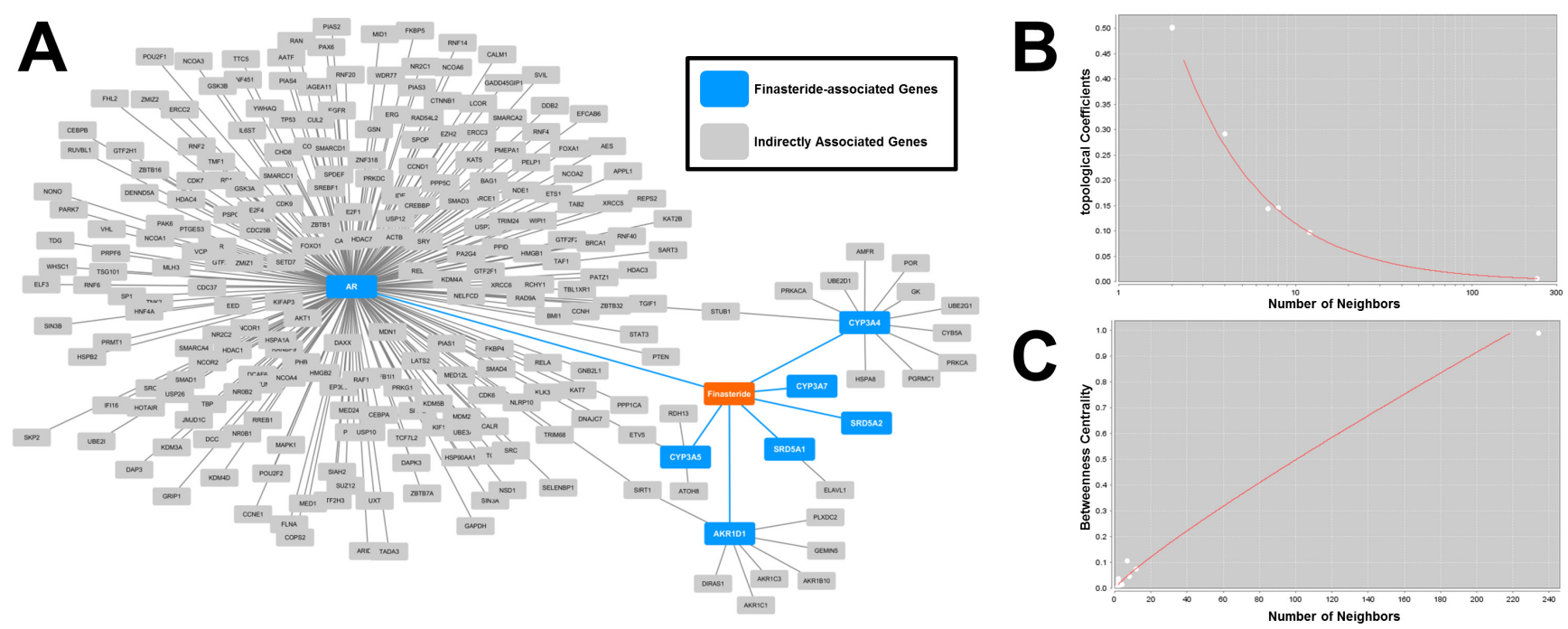

Figure 1: Visualization and analysis of drug-gene network. A. The finasteride-associated genes and indirectly associated genes were integrated into a network. A node denoted a drug (i.e., finasteride) or a gene. An edge represented an interaction between two nodes. B. The topological coefficients followed the power law distributions, with an $\mathrm{R}^{2}=0.99$. C. The betweenness centrality followed the power law distributions, with an $\mathrm{R}^{2}=0.84$. 
biosynthesis' pathway $\left(P=7.16 \times 10^{-9}\right)$, 'intracellular steroid hormone receptor signaling pathway' $(P=$ $\left.1.24 \times 10^{-47}\right)$ and 'androgen receptor signaling pathway' $\left(P=2.00 \times 10^{-44}\right)$. These findings make very important sense, since steroid hormones, specially androgen, are well known to play an fundamental role in maintaining male sexual function [34, 35]. Regarding reproductive toxicity in women, we identified two KEGG pathways that were highly enriched with FAGs and IAGs, including 'oocyte meiosis' $\left(P=1.43 \times 10^{-5}\right)$ and 'progesteronemediated oocyte maturation' $\left(P=3.27 \times 10^{-5}\right)$. Inadequate secretion of progesterone has been proposed as a cause of spontaneous abortion $[36,37]$. These results indicated that finasteride could profoundly affect the normal reproductive function by acting on specific key genes in relevant pathways.

\section{DISCUSSION}

Most alopecia cases with the intent of receiving treatment may choose either finasteride or minoxidil, since they are the two major drug products approved by FDA for marketing. Therefore, the differences between these two drugs are always a compelling clinical issue. In previous studies, a lot of efforts have been made to unveil their difference in efficacy. However, not only efficacy but also toxicity of drugs should be fully understood to determine the remedy with optimal benefit-to-risk ratio [38]. Clinical trials with only a limited number of patients and a relatively short period of treatment may not give the full picture of safety risks, which need to be supplemented by large-scale post-marketing data collected from general population. As an excellent example of post-marketing data source, OpenFDA platform provided formatted and annotated information about drug generic names, patient characteristics and adverse reactions. Such information enabled us to efficiently explore the adverse events related to finasteride and minoxidil. For both genders, finasteride was concurrent with reproductive adverse effects more often than minoxidil, which reiterated the importance of studying undesirable drug effects on reproductive system [39]. And the toxicological differences between finasteride and minoxidil should be seriously considered when selecting treatment regimen.

Among male cases, a relatively higher risk of sexual dysfunction was observed with exposure to finasteride, which corroborated the information in FDA-approved drug label [28] and the results of previous controlled trials [40]. These andrological adverse effects may be closely related to the pharmacological mechanisms of finasteride. As a drug originally developed for benign prostatic hyperplasia, finasteride could influence androgen activity, which may profoundly affect sexual function of men. Apart from reproductive toxicity in men, we also found that finasteride was more likely to induce psychiatric reactions, and minoxidil was more likely to induce dermatitis and chorioretinopathy. These results were consistent with previous clinical observation [41-43] and warranted in-depth toxicologically research.

In the meantime, reproductive toxicity of finasteride was also reported by female alopecia cases. In the FDAapproved drug label, it has been warned that finasteride may cause birth defects in fetus [28]. Our analysis showed that besides birth defects, drug-induced abortion and disorder of uterus were also significantly associated with finasteride. Although finasteride was approved for alopecia in men only, the female cases in FAERS revealed that finasteride may also be used by women under some circumstances. Usually, the negative cosmetic effect of hair loss may cause greater psychological stress in women than in men. As alopecia is becoming a clinical problem increasingly common in women [44], some female alopecia cases may have strong willing try every possible remedy, even the effect of finasteride on women remains largely unclear. This observation reminded us that more attention should be paid to unapproved treatment of alopecia. And subsequent research will be required to elucidate how finasteride may affect female reproductive system.

Accumulated researches have demonstrated that an integrative analysis of drug-gene network can provide deep insights into the molecular toxicological mechanisms of drugs. Therefore, we extracted and linked a set of human genes directly or indirectly interrupted by finasteride. The topology characteristics showed that the finasteride-centered network were scale-free just as true biological networks. In this network, we found that finasteride was closely related to androgen receptor (gene symbol AR) and several other genes, thus disturb a network significantly associated with a number of functional annotations (e.g., sex hormone signaling and oocyte maturation). These functional evidences, from the network aspect, can illustrate the toxic effect of finasteride on male and female reproductive systems, thus providing objectives for follow-up research.

Despite of valuable discoveries, some inherent limitations of FAERS data should be borne in mind. First, the number of a certain adverse effect may not directly measure the risk of drug in reality, since spontaneous reporting may not represent the completeness of case finding [45]. Moreover, even if reporting is complete, it is hardly possible to enumerate the underlying population of drugs users as the denominator. Therefore, the proportional reporting ratio that resembled a risk ratio in its distribution and interpretation was calculated as an alternative measure. Regarding the adverse reaction of interest, the reporting rate of finasteride users was compared to the rate of minoxidil users. In this way, the difference between these two drugs could be qualitatively detected. But the reliability of PRRs may still be jeopardized by confounding factors such as age, comorbidities, and prior treatment history. Second, it has 
been reported that finasteride and minoxidil were used in combination in some cases $[16,46]$. Nevertheless, the number of adverse event reports concurrent with both finasteride and minoxidil was too low in FAERS data to achieve an acceptable statistical power. Therefore, we would suggest that other clinical data regarding the combined treatment of finasteride and minoxidil should be scrutinized to better address the safety issue of drug combination. Third, the close association between high drug dose and incidence of adverse drug reaction has been demonstrated by prior studies [47]. However, dosage information was not analyzed in the present study, because it was not clearly recorded in most FAERS reports. So we would expect the dosage factor in toxicity to be examined in other clinical data of alopecia cases. Fourth, the analysis on drug-gene interactions led to a finasteride-centered network, which provided new clues with regard to the reproductive toxicity of finasteride. The next step should involve carefully selecting specific candidate genes from the network for in-depth research, such as drug-induced differential gene expression [48] and mitochondrial DNA damage [49].

All above concerns reminded us that the current results are only the beginning, rather than a complete conclusion, of the toxicological research about alopecia treatments. First of all, while interpreting the P-values and PRRs judiciously, further large-scale cohort studies will be required to quantitatively confirm the incidence rate of various adverse effects of finasteride or minoxidil. Also, follow-up experimental research could be performed on the basis of our analysis, so as to better understand the reproductive toxicity of finasteride. For instance, it has been well known that drug could induce adverse reactions by unexpectedly interacting with off-target proteins and perturbing downstream signaling pathways. Therefore, the off-targets $[50,51]$ and genomic expression changes $[52,53]$ related to finasteride could be further explored. Moreover, it should be noticed that finasteride was approved by FDA for oral use, while minoxidil was approved for topical use. Previous research indicated that the route of administration could greatly influence the degree of toxicity, and oral administration was usually more risky than external use [54]. Because of that, it is worth trying to change the route of administration [55] or adjust the oral dosage [56] of finasteride, so as to reduce the toxic effects.

Taken together, our analysis on FAERS data provided a unique perspective on the toxicological differences between finasteride and minoxidil. In particular, finasteride was more reported for reproductive adverse effects among both women and men, some of which have yet to be warned in FDA-approved drug label. These findings should be considered to effectively improve alopecia treatment and post-marketing regulation of drug products. In addition, the present study will foster further clinical and experimental research on the underlying mechanisms of drug-induced reproductive toxicity.

\section{MATERIALS AND METHODS}

\section{Query of FAERS data}

The original reports restored in FAERS were queried from OpenFDA platform following the official tutorial (https://open.fda.gov/api/reference/). The events related to either finasteride or minoxidil, and submitted from January 2004 to June 2014 were retrieved. Since both finasteride and minoxidil have indication other than alopecia, the adverse events were included only if the drug indication was annotated with either of the following OpenFDA query terms: "ALOPECIA", "ALOPECIA AREATA", "ALOPECIA EFFLUVIUM", "ALOPECIA SCARRING", "ALOPECIA TOTALIS", "ALOPECIA UNIVERSALIS", "ANDROGENETIC ALOPECIA", "DIFFUSE ALOPECIA", which were coded using MedDRA terminology (http://www.meddra.org/). Taking gender difference in to consideration, the adverse events occurred among female and male cases were queried and analyzed separately. Those reports without clear information of patient's gender were not included in this analysis.

\section{Proportional reporting ratio (PRR)}

The top 10 most commonly reported adverse events among finasteride users or by minoxidil users were examined. To compare the risk of finasteride and minoxidil, the proportional reporting ratio (PRR) was calculated. Consider a hypothetical situation in which adverse effect $\mathrm{X}$ was reported by $\mathrm{A}_{1}$ alopecia cases among all the $\mathrm{A}_{0}$ cases exposed to finasteride. On the other hand, the same adverse effect was reported by $\mathrm{B}_{1}$ cases among all the $\mathrm{B}_{0}$ cases exposed to minoxidil. Therefore, The PRR for adverse effect $\mathrm{X}$ should be computed as follows:

$$
P R R_{X}=\frac{A_{1} / A_{0}}{B_{1} / B_{0}}
$$

The null hypothesis was formulated as $\mathrm{PRR}_{\mathrm{X}}=1$, suggesting that adverse effect $X$ was not more frequently concurrent with one drug than the other. The P-value was calculated with two-tailed Fisher's exact test to determine whether the null hypothesis was valid. And the 95\% confidence interval (CI) of PRR was calculated as

$$
\begin{aligned}
& 95 \% C I_{\text {lower }}=\mathrm{e}^{\ln \left(P R R_{X}\right)-1.96 \times \sqrt{\frac{1}{A_{1}}+\frac{1}{B_{1}}-\frac{1}{A_{0}}-\frac{1}{B_{0}}}} \\
& 95 \% C I_{\text {upper }}=\mathrm{e}^{\ln \left(P R R_{X}\right)+1.96 \times \sqrt{\frac{1}{A_{1}}+\frac{1}{B_{1}}-\frac{1}{A_{0}}-\frac{1}{B_{0}}}}
\end{aligned}
$$

A PRR significantly greater than its null value of 1 indicated a finasteride-biased risk of adverse effect X. Otherwise, a PRR significantly lower than 1 indicated a 
minoxidil-biased risk.

\section{Analysis of drug-gene network}

A drug-gene network was generated with three types of nodes, including drug (i.e., finasteride), drugassociated gene, and neighbor proteins interacting with drug-associated genes. First, finasteride was queried in the PharmGKB database (https://www.pharmgkb.org/) [57] and the DrugBank database [58] to extract drug-associated genes according to various published evidences. Then, the proteins interacting with the above drug-associated genes were extracted from the BioGRID database (version 3.4.138, http://thebiogrid.org/) [59]. Finally, nodes interacting with each other were linked with an edge to construct a network. The visualization and topological analysis of this drug-gene network was deployed with the Cytoscape software (version 3.4.0, http://www. cytoscape.org/) [60]. All genes in this network were input into the WEB-based GEne SeT AnaLysis Toolkit (WebGestalt, http://bioinfo.vanderbilt.edu/webgestalt/) [61]. Hypergeometric test was performed to evaluate the statistical significance of enrichment for KEGG pathways (http://www.genome.jp/kegg/pathway.html) [62] and Gene Ontology terms (http://geneontology.org/) [63]. The raw P-values were adjusted for multiple testing with the Benjamini-Hochberg procedure.

\section{ACKNOWLEDGMENTS}

Drs. $\mathrm{Wu}$ and $\mathrm{Yu}$ designed the study and performed statistical analysis. Drs. Wu and Li prepared the first draft. Dr. Yu revised the manuscript. And all authors contributed to the final version.

\section{CONFLICTS OF INTEREST}

The authors declare no conflicts of interest regarding the content of this article.

\section{REFERENCES}

1. Olsen EA, Messenger AG, Shapiro J, Bergfeld WF, Hordinsky MK, Roberts JL, Stough D, Washenik K and Whiting DA. Evaluation and treatment of male and female pattern hair loss. J Am Acad Dermatol. 2005; 52(2):301311.

2. Passchier J, Erdman J, Hammiche F and Erdman RA. Androgenetic alopecia: stress of discovery. Psychol Rep. 2006; 98(1):226-228.

3. Seidel P, Remus M, Delacher M, Grigaravicius P, Reuss DE, Frappart L, von Deimling A, Feuerer M, Abdollahi A and Frappart PO. Epidermal Nbn deletion causes premature hair loss and a phenotype resembling psoriasiform dermatitis. Oncotarget. 2016; 7:23006-23018. doi: 10.18632/oncotarget.8470.

4. McElwee KJ, Gilhar A, Tobin DJ, Ramot Y, Sundberg JP, Nakamura M, Bertolini M, Inui S, Tokura Y, King LE, Jr., Duque-Estrada B, Tosti A, Keren A, et al. What causes alopecia areata? Exp Dermatol. 2013; 22(9):609-626.

5. Crabtree JS, Kilbourne EJ, Peano BJ, Chippari S, Kenney T, McNally C, Wang W, Harris HA, Winneker RC, Nagpal $\mathrm{S}$ and Thompson CC. A mouse model of androgenetic alopecia. Endocrinology. 2010; 151(5):2373-2380.

6. Weger N and Schlake T. Igf-I signalling controls the hair growth cycle and the differentiation of hair shafts. J Invest Dermatol. 2005; 125(5):873-882.

7. El-Domyati M, Attia S, Saleh F and Abdel-Wahab H. Androgenetic alopecia in males: a histopathological and ultrastructural study. J Cosmet Dermatol. 2009; 8(2):83-91.

8. Drake L, Hordinsky M, Fiedler V, Swinehart J, Unger WP, Cotterill PC, Thiboutot DM, Lowe N, Jacobson C, Whiting D, Stieglitz S, Kraus SJ, Griffin EI, et al. The effects of finasteride on scalp skin and serum androgen levels in men with androgenetic alopecia. J Am Acad Dermatol. 1999; 41(4):550-554.

9. Wester RC, Maibach HI, Guy RH and Novak E. Minoxidil stimulates cutaneous blood flow in human balding scalps: pharmacodynamics measured by laser Doppler velocimetry and photopulse plethysmography. J Invest Dermatol. 1984; 82(5):515-517.

10. Lachgar S, Charveron M, Gall Y and Bonafe JL. Minoxidil upregulates the expression of vascular endothelial growth factor in human hair dermal papilla cells. Br J Dermatol. 1998; 138(3):407-411.

11. Mori $\mathrm{O}$ and Uno $\mathrm{H}$. The effect of topical minoxidil on hair follicular cycles of rats. J Dermatol. 1990; 17(5):276-281.

12. Buhl AE, Waldon DJ, Conrad SJ, Mulholland MJ, Shull KL, Kubicek MF, Johnson GA, Brunden MN, Stefanski KJ, Stehle RG and et al. Potassium channel conductance: a mechanism affecting hair growth both in vitro and in vivo. J Invest Dermatol. 1992; 98(3):315-319.

13. Dawson SJ and Chivers ML. Gender-specificity of solitary and dyadic sexual desire among gynephilic and androphilic women and men. J Sex Med. 2014; 11(4):980-994.

14. Tagalakis V, Kondal D, Ji Y, Boivin JF, Moride Y, Ciampi A and Kahn SR. Men had a higher risk of recurrent venous thromboembolism than women: a large population study. Gend Med. 2012; 9(1):33-43.

15. Arca E, Acikgoz G, Tastan HB, Kose O and Kurumlu Z. An open, randomized, comparative study of oral finasteride and $5 \%$ topical minoxidil in male androgenetic alopecia. Dermatology. 2004; 209(2):117-125.

16. $\mathrm{Hu} \mathrm{R}, \mathrm{Xu} \mathrm{F}$, Sheng Y, Qi S, Han Y, Miao Y, Rui W and Yang Q. Combined treatment with oral finasteride and topical minoxidil in male androgenetic alopecia: a randomized and comparative study in Chinese patients. Dermatol Ther. 2015.

17. Khandpur S, Suman M and Reddy BS. Comparative efficacy 
of various treatment regimens for androgenetic alopecia in men. J Dermatol. 2002; 29(8):489-498.

18. Oliveira-Soares R, JM ES, Correia MP and Andre MC. Finasteride $5 \mathrm{mg}$ /day Treatment of Patterned Hair Loss in Normo-androgenetic Postmenopausal Women. Int J Trichology. 2013; 5(1):22-25.

19. Price VH, Roberts JL, Hordinsky M, Olsen EA, Savin R, Bergfeld W, Fiedler V, Lucky A, Whiting DA, Pappas F, Culbertson J, Kotey P, Meehan A, et al. Lack of efficacy of finasteride in postmenopausal women with androgenetic alopecia. J Am Acad Dermatol. 2000; 43(5 Pt 1):768-776.

20. Kim WJ, Song M, Ko HC, Kim BS and Kim MB. Efficacy of Finasteride $1.25 \mathrm{mg}$ on Female Pattern Hair Loss; Pilot Study. Ann Dermatol. 2012; 24(3):370-372.

21. Piraccini B, Starace M, Alessandrini A, Guarrera M, Fiorucci MC and Lorenzi S. [Efficacy and tolerability of $5 \%$ minoxidil solution (Carexidil(R)) in male and female androgenetic alopecia: a 6-month open multicentric study]. G Ital Dermatol Venereol. 2011; 146(6 Suppl 1):1-8.

22. Lucky AW, Piacquadio DJ, Ditre CM, Dunlap F, Kantor I, Pandya AG, Savin RC and Tharp MD. A randomized, placebo-controlled trial of $5 \%$ and $2 \%$ topical minoxidil solutions in the treatment of female pattern hair loss. J Am Acad Dermatol. 2004; 50(4):541-553.

23. Belknap SM, Aslam I, Kiguradze T, Temps WH, Yarnold PR, Cashy J, Brannigan RE, Micali G, Nardone B and West DP. Adverse Event Reporting in Clinical Trials of Finasteride for Androgenic Alopecia: A Meta-analysis. JAMA Dermatol. 2015; 151(6):600-606.

24. Wang K, Wan M, Wang RS and Weng Z. Opportunities for Web-based Drug Repositioning: Searching for Potential Antihypertensive Agents with Hypotension Adverse Events. Journal of medical Internet research. 2016; 18(4):e76.

25. Yang L, Wang K, Chen J, Jegga AG, Luo H, Shi L, Wan C, Guo X, Qin S, He G, Feng G and He L. Exploring off-targets and off-systems for adverse drug reactions via chemical-protein interactome--clozapine-induced agranulocytosis as a case study. Plos Comput Biol. 2011; 7(3):e1002016.

26. Hoffman KB, Kraus C, Dimbil M and Golomb BA. A survey of the FDA's AERS database regarding muscle and tendon adverse events linked to the statin drug class. PLoS One. 2012; 7(8):e42866.

27. Shu M, Zai X, Zhang B, Wang $R$ and Lin Z. Hypothyroidism Side Effect in Patients Treated with Sunitinib or Sorafenib: Clinical and Structural Analyses. PloS one. 2016; 11(1):e0147048.

28. http://dailymed.nlm.nih.gov/dailymed/drugInfo. cfm?setid=3444ec5f-cc70-488a-9462-61945ef77148.

29. Evans SJ, Waller PC and Davis S. Use of proportional reporting ratios (PRRs) for signal generation from spontaneous adverse drug reaction reports. Pharmacoepidemiol Drug Saf. 2001; 10(6):483-486.

30. Gautier L, Taboureau O and Audouze K. The effect of network biology on drug toxicology. Expert opinion on drug metabolism \& toxicology. 2013; 9(11):1409-1418.

31. Ludovini V, Bianconi F, Siggillino A, Piobbico D, Vannucci J, Metro G, Chiari R, Bellezza G, Puma F, Della Fazia MA, Servillo G and Crino L. Gene identification for risk of relapse in stage I lung adenocarcinoma patients: a combined methodology of gene expression profiling and computational gene network analysis. Oncotarget. 2016; 7:30561-30574. doi: 10.18632/oncotarget.8723.

32. Wu B, Li C, Du Z, Yao Q, Wu J, Feng L, Zhang P, Li S, $\mathrm{Xu} \mathrm{L}$ and Li E. Network based analyses of gene expression profile of LCN2 overexpression in esophageal squamous cell carcinoma. Scientific reports. 2014; 4:5403.

33. Barabasi AL and Oltvai ZN. Network biology: understanding the cell's functional organization. Nature reviews Genetics. 2004; 5(2):101-113.

34. Traish AM, Abu-Zahra H and Guay AT. The brain, the penis and steroid hormones: clinical correlates with endothelial dysfunction. Current pharmaceutical design. 2008; 14(35):3723-3736.

35. Kohler TS, Kim J, Feia K, Bodie J, Johnson N, Makhlouf A and Monga M. Prevalence of androgen deficiency in men with erectile dysfunction. Urology. 2008; 71(4):693-697.

36. Hussain M, El-Hakim S and Cahill DJ. Progesterone supplementation in women with otherwise unexplained recurrent miscarriages. Journal of human reproductive sciences. 2012; 5(3):248-251.

37. Haas DM and Ramsey PS. Progestogen for preventing miscarriage. The Cochrane database of systematic reviews. 2013; (10):CD003511.

38. Simon LS. Pharmacovigilance: towards a better understanding of the benefit to risk ratio. Ann Rheum Dis. 2002; 61 Suppl 2:ii88-89.

39. Schaefer C, Ornoy A, Clementi M, Meister R and Weber-Schoendorfer C. Using observational cohort data for studying drug effects on pregnancy outcome-methodological considerations. Reprod Toxicol. 2008; 26(1):36-41.

40. Mella JM, Perret MC, Manzotti M, Catalano HN and Guyatt G. Efficacy and safety of finasteride therapy for androgenetic alopecia: a systematic review. Arch Dermatol. 2010; 146(10):1141-1150.

41. Irwig MS. Depressive symptoms and suicidal thoughts among former users of finasteride with persistent sexual side effects. J Clin Psychiatry. 2012; 73(9):1220-1223.

42. Friedman ES, Friedman PM, Cohen DE and Washenik K. Allergic contact dermatitis to topical minoxidil solution: etiology and treatment. J Am Acad Dermatol. 2002; 46(2):309-312.

43. Scarinci F, Mezzana P, Pasquini P, Colletti M and Cacciamani A. Central chorioretinopathy associated with topical use of minoxidil 2\% for treatment of baldness. Cutan Ocul Toxicol. 2012; 31(2):157-159. 
44. Camacho-Martinez FM. Hair loss in women. Semin Cutan Med Surg. 2009; 28(1):19-32.

45. Fontanarosa PB, Rennie D and DeAngelis CD. Postmarketing surveillance--lack of vigilance, lack of trust. Jama. 2004; 292(21):2647-2650.

46. Chandrashekar BS, Nandhini T, Vasanth V, Sriram R and Navale S. Topical minoxidil fortified with finasteride: An account of maintenance of hair density after replacing oral finasteride. Indian Dermatol Online J. 2015; 6(1):17-20.

47. Weng Z, Wang K, Li H and Shi Q. A comprehensive study of the association between drug hepatotoxicity and daily dose, liver metabolism, and lipophilicity using 975 oral medications. Oncotarget. 2015; 6:17031-17038. doi: 10.18632/oncotarget.4400.

48. Wang K, Fan DD, Jin S, Xing NZ and Niu YN. Differential expression of 5-alpha reductase isozymes in the prostate and its clinical implications. Asian journal of andrology. 2014; 16(2):274-279.

49. Xu C, Liu Q, Liu H, Zhang C, Shao W and Gu A. Toxicological assessment of multi-walled carbon nanotubes in vitro: potential mitochondria effects on male reproductive cells. Oncotarget. 2016;7:39270-39278. doi: 10.18632/ oncotarget.9689.

50. Luo H, Chen J, Shi L, Mikailov M, Zhu H, Wang K, He L and Yang L. DRAR-CPI: a server for identifying drug repositioning potential and adverse drug reactions via the chemical-protein interactome. Nucleic acids research. 2011; 39(Web Server issue):W492-498.

51. Yang L, Wang KJ, Wang LS, Jegga AG, Qin SY, He G, Chen J, Xiao Y and He L. Chemical-protein interactome and its application in off-target identification. Interdiscip Sci. 2011; 3(1):22-30.

52. Wang K, Weng Z, Sun L, Sun J, Zhou SF and He L. Systematic drug safety evaluation based on public genomic expression (Connectivity Map) data: myocardial and infectious adverse reactions as application cases. Biochem Biophys Res Commun. 2015; 457(3):249-255.

53. Li Z, Qin T, Wang K, Hackenberg M, Yan J, Gao Y, Yu LR, Shi L, Su Z and Chen T. Integrated microRNA, mRNA, and protein expression profiling reveals microRNA regulatory networks in rat kidney treated with a carcinogenic dose of aristolochic acid. BMC Genomics. 2015; 16:365.

54. Grossberg G, Sadowsky C, Frostl H, Frolich L, Nagel J, Tekin S, Zechner S, Ros J and Orgogozo JM. Safety and tolerability of the rivastigmine patch: results of a 28-week open-label extension. Alzheimer Dis Assoc Disord. 2009; 23(2):158-164.
55. Caserini M, Radicioni M, Leuratti C, Terragni E, Iorizzo M and Palmieri R. Effects of a novel finasteride $0.25 \%$ topical solution on scalp and serum dihydrotestosterone in healthy men with androgenetic alopecia. Int J Clin Pharmacol Ther. 2016; 54(1):19-27.

56. Roberts JL, Fiedler V, Imperato-McGinley J, Whiting D, Olsen E, Shupack J, Stough D, DeVillez R, Rietschel R, Savin R, Bergfeld W, Swinehart J, Funicella T, et al. Clinical dose ranging studies with finasteride, a type 2 5alpha-reductase inhibitor, in men with male pattern hair loss. J Am Acad Dermatol. 1999; 41(4):555-563.

57. Whirl-Carrillo M, McDonagh EM, Hebert JM, Gong L, Sangkuhl K, Thorn CF, Altman RB and Klein TE. Pharmacogenomics knowledge for personalized medicine. Clinical pharmacology and therapeutics. 2012; 92(4):414417.

58. Law V, Knox C, Djoumbou Y, Jewison T, Guo AC, Liu Y, Maciejewski A, Arndt D, Wilson M, Neveu V, Tang A, Gabriel G, Ly C, et al. DrugBank 4.0: shedding new light on drug metabolism. Nucleic acids research. 2014; 42(Database issue):D1091-1097.

59. Oughtred R, Chatr-aryamontri A, Breitkreutz BJ, Chang CS, Rust JM, Theesfeld CL, Heinicke S, Breitkreutz A, Chen D, Hirschman J, Kolas N, Livstone MS, Nixon J, et al. BioGRID: A Resource for Studying Biological Interactions in Yeast. Cold Spring Harbor protocols. 2016; 2016(1):pdb top080754.

60. Kohl M, Wiese S and Warscheid B. Cytoscape: software for visualization and analysis of biological networks. Methods in molecular biology. 2011; 696:291-303.

61. Zhang B, Kirov S and Snoddy J. WebGestalt: an integrated system for exploring gene sets in various biological contexts. Nucleic acids research. 2005; 33(Web Server issue):W741-748.

62. Kanehisa M, Sato Y, Kawashima M, Furumichi M and Tanabe M. KEGG as a reference resource for gene and protein annotation. Nucleic acids research. 2016; 44(D1):D457-462.

63. Gene Ontology C. Gene Ontology Consortium: going forward. Nucleic acids research. 2015; 43(Database issue):D1049-1056. 